\title{
EDUCAÇÃO AMBIENTAL E SUA NORMATIVIDADE SIMBÓLICA ${ }^{1}$
}

\author{
Magno Federici Gomes \\ Pós-doutor em Direito Público e Educação pela \\ Universidade Nova de Lisboa-Portugal. Pós-doutor em \\ Direito Civil e Processual Civil, Doutor em Direito e \\ Mestre em Direito Processual, pela Universidad de \\ Deusto-Espanha. Mestre em Educação pela PUC Minas. \\ Professor do Mestrado Acadêmico em Direito Ambiental e \\ Sustentabilidade na Escola Superior Dom Helder Câmara. \\ Professor Adjunto da PUC Minas e Professor Titular \\ licenciado da Faculdade de Direito Arnaldo Janssen. \\ Advogado Sócio do Escritório Moraes \& Federici \\ Advocacia Associada. Integrante dos grupos de pesquisa: \\ Regulação Ambiental da Atividade Econômica \\ Sustentável (REGA)/CNPQ-BRA, Centro de Investigação \\ \& Desenvolvimento sobre Direito e Sociedade (CEDIS)/ \\ FCT-PT e Núcleo de Estudos sobre Gestão de Políticas \\ Públicas (NEGESP)/CNPQ-BRA. \\ federici@pucminas.br \\ Vânia Ágda de Oliveira Carvalho \\ Mestra em Direito Ambiental e Desenvolvimento \\ Sustentável pela Escola Superior Dom Helder Câmara. \\ Especialista em Direito Civil e Processual Civil pela \\ Faculdade de Direito do Vale do Rio Doce. Graduada em \\ Direito pela Faculdade de Ciências Jurídicas e Sociais \\ Vianna Júnior e em Gestão de Recursos Humanos pela \\ Faculdade Estácio de Sá. Bolsista/pesquisadora \\ FAPEMIG. Membro do Grupo de Pesquisa "Direitos \\ Humanos, Meio Ambiente, Epistemologia Ambiental e \\ dos Direitos Humanos e processos esde construção da \\ Sustentabilidade". \\ vaniaagdaocarvalho@gmail.com
}

RESUMO: A educação ambiental é instrumento que, por meio de políticas públicas, materializa visão sistêmica de desenvolvimento sustentável. Assim, esse artigo analisará a sua normatividade, instituída pela Constituição da República de 1988 (CR/1988), examinando os principais pontos de sua regulação jurídica com o objetivo de ponderá-la enquanto meio a assegurar efetividade do direito ao ambiente ecologicamente equilibrado. Concluiu-se pela ausência de efetivação da Lei de Educação Ambiental, que necessita de atitude positiva do Estado que não destina seriedade ao princípio constitucional da educação ambiental. O método usado foi o teórico-jurídico com raciocínio dedutivo e técnica de pesquisa bibliográfica e documental.

PALAVRAS-CHAVE: Educação ambiental. Simbologia normativa. Políticas públicas.

1 Trabalho financiado pelo Edital no 05/2016 (Projeto $n^{\circ}$ FIP 2016/11173-S2) do FIP/PUC MINAS, resultante dos Grupos de Pesquisas (CNPQ): Regulação Ambiental da Atividade Econômica Sustentável (REGA), NEGESP e CEDIS (FCT-PT). 


\section{Environmental education and your normative symbology}

ABSTRACT: Environmental education is an instrument that, through public policies, materializes a systemic vision of sustainable development. Thus, this article will analyze its normativity, established by the Constitution of the Republic of 1988 (CR / 1988), examining the main points of its legal regulation in order to consider it as a means to ensure the effectiveness of the right to an ecologically balanced environment. It was concluded by the lack of implementation of the Environmental Education Law, which requires a positive attitude of the State that does not assign seriousness to the constitutional principle of environmental education. The method used was the theoretical-juridical with deductive reasoning and bibliographical and documentary research technique

KEYWORDS: Environmental education. Normative symbology. Public policy.

\section{INTRODUÇÃo}

Devido a busca incessante pelo crescimento econômico, aliado à capacidade humana em acumular riquezas, o meio ambiente atingiu um nível de degradação vultuoso, despertando a necessidade de preservação ambiental.

Não se havia pensado em valorar os recursos advindos da natureza. Parecia longínquo, por exemplo, o dia em que se pensaria esgotável a água e que se aprouvesse viável destinar valor econômico a ela em prol de preservá-la.

Nesse prisma, grande desafio enfrentado pelo Direito, em especial pelo Direito ambiental e também pelo Direito econômico, consiste na capacidade em coadunar as atividades humanas aos limites da natureza quanto à esgotabilidade de seus recursos.

Um dos meios a auxiliar as ferramentas para o intento, ou talvez, basilar a estas, é a educação ambiental que, sem o desígnio de torná-la a panaceia de todos os problemas ambientais, pode corroborar para a mudança de paradigmas, no sentido de modificar o comportamento da espécie humana em benefício de sua própria preservação.

Por meio da educação ambiental a sociedade pode formar uma consciência ecológica crítica, atingindo uma valorização do meio ambiente e, consequentemente, sua preservação, visando um desenvolvimento sustentável para que se possa desfrutá-lo sem extinguir seus recursos. Ademais, ao tornar obrigatória a promoção da educação ambiental, a Constituição da República de 1988 (CR/1988), orienta-se pela suposição de que para defender e preservar o meio ambiente não basta o uso de mecanismos de sanção e de promoção do direito, sendo necessário promover a educação e a conscientização pública.

Nesse viés, tem-se que o objetivo do presente artigo consiste em efetuar análise da normatividade destinada à educação ambiental, instituída pela CR/1988. Tomou-se por base a Lei Federal $n^{\circ} 9.795 / 1999$, procurando examinar os principais pontos da regulação jurídica com o objetivo primordial de coadunar a educação ambiental enquanto meio para assegurar a efetividade do direito ao ambiente ecologicamente equilibrado, preconizado pelo art. 225, caput, da CR/1988.

Esse artigo seguirá uma linha de exposição em cinco capítulos. No primeiro capítulo, após fase introdutória, será analisada a questão da normatividade simbólica, bem como apresentada a relevância do uso do método interpretativo de Dworkin (2002), em contraponto ao positivismo puro, perpassando pela teoria do transconstitucionalismo de Neves (1999). No 
segundo capítulo ocorrerá abordagem quanto ao caráter principiológico da educação ambiental, em análise pautada pela CR/1988.

O terceiro capítulo trará os atos normativos destinados à educação ambiental e a abordagem quanto a sua efetivação, tomando por base o arcabouço apresentado no artigo. Finalmente, no capítulo subsequente, efetuar-se-á uma retomada ao debate contido no problema em tela.

Após o desenrolar dos capítulos, serão apresentadas as considerações finais que se alcançaram com o desenvolver do tema.

Para o desenvolvimento desse artigo será adotado o método teórico-jurídico com raciocínio dedutivo e técnica de pesquisa bibliográfica e documental.

\section{Simbologia nORMATIVA}

A Constituição social passou a disciplinar os direitos econômicos e sociais, além dos já abarcados direitos e liberdades civis, de modo que houve, segundo Pimenta (1999, p. 139), um alargamento de matéria constitucional, vindo a apresentar as chamadas normas programáticas.

Pontes de Miranda apresenta conceito para norma programática como sendo uma norma “[...] cujo legislador, constituinte ou não, em vez de editar regra jurídica de aplicação concreta, apenas traça linhas diretoras, pelas quais se hão de orientar os poderes públicos" (PONTES DE MIRANDA apud PIMENTA, 2003, p. 136). Pode-se constatar, assim, que a norma programática apresenta princípios diretivos.

Silva (2001, p. 81-82) apresenta a classificação tradicional quanto às normas constitucionais brasileiras, as separando em normas de eficácia plena (aplicáveis desde sua entrada em vigor, de maneira imediata e integral), as de eficácia contida (possuem aplicação imediata, podendo, porém, serem restringidas por leis infraconstitucionais, sendo, assim, de aplicação não integral) e as normas de eficácia limitada (aquelas que necessitam de outra norma para regulamentar sua aplicabilidade), sendo que as normas programáticas se enquadram exatamente na classificação das normas de eficácia limitada.

A compatibilização de elementos instrumentais de simbolismo caracteriza a força de determinada legislação e o ordenamento jurídico é alicerçado em ambas variáveis. Todavia, quando a eficácia normativa é desconsiderada em favor do efeito simbólico, surgem dificuldades relacionadas à consequência hipertrófica ocasionada pela simbologia da norma.

Ou seja, normas são criadas sem que sejam, de fato, eficazes, sendo que, em algumas vezes, o Poder Legislativo atua em prol unicamente de tender uma situação social emergente. Corrobora com tal entendimento:

\footnotetext{
Ora, no caso das normas programáticas o sucesso está diretamente relacionado com o encobrimento ideológico, vale dizer, quando se editam tais normas o escopo não é a obediência, a submissão, e sim a satisfação ideológica, traduzida no apaziguamento das consciências políticas, posto que ais normas são síntese de interesses contrapostos, antagônicos, de grupos sociais (PIMENTA, 1999, p. 162).
}

Em consequência, ocorre o fenômeno da existência exacerbada de textos legais, com a criação de leis inaplicáveis, vindo a causar na população um cepticismo nos poderes públicos.

Nesse mesmo viés, pode-se aferir o ingresso, na Constituição, de normas de contento simbólico, resultando na constitucionalização simbólica, conforme preconiza Neves (1999). Tal concepção está relacionada às normas programáticas, de eficácia limitada, referindo-se a 
orientação aos órgãos estatais quanto ao fim almejado na norma, que à regulação imediata concernente a interesses específicos, ou, como já dito, apresentado apenas princípios diretivos.

Referente às normas programáticas com finalidade social é mais perceptível a simbologia normativa, no que tange ao conteúdo constitucional, como o direito à educação, vinculado ao tema do presente artigo, qual seja, educação ambiental e que foram abarcados pela Constituição social.

Assim, nota-se negligência quanto à missão jurídico-instrumental em alguns direitos sociais constantes das normas constitucionais programáticas, cuja efetuação almeja do Estado uma ação positiva, explicitando o caráter simbólico constitucional.

Há doutrinadores, como Canotilho (2003, p. 1.176-1.177), que estabelecem que as normas programáticas possuem a mesma estrutura das demais normas jurídicas, as diferenciando no critério de necessidade de leis que as regulamentem. Ou seja, dependem de ações futuras para destinar eficácia às mesmas. Entretanto, tem-se que as normas programáticas são dotadas de eficácia jurídica, "porque qualquer norma constitucional deve considerar-se obrigatória perante quaisquer órgãos do poder político" (CANOTILHO, 2003, p. 1.177). Não se pode falar, dessa forma, em eficácia programática, mas tão somente em necessidade de regulamentação, sem vinculá-las à ausência de eficácia.

Tal preceito elencando por Canotilho (2003) é seguido por Gomes (2012), que evidencia:

Pode-se concluir, então, que as normas constitucionais programáticas devem ser
consideradas como normas aplicáveis, visto quem do contrário, abre-se espaço para
que a legislação infraconstitucional vá em sentido contrário ao da CR/88, o que não
se pode admitir em um Sociedade democrática, pautada pela supremacia da Consti-
tuição e pela dignidade da pessoa humana (GOMES, 2012, p. 101).

É também o preconizado nos ensinamentos de Pimenta (1999, p. 152) ao confrontar eficácia programada com eficácia obrigatória, relatando que “[...] qualquer norma constitucional deve desde logo ser obrigatória nos confrontos de qualquer potestade estatal discricionária, compreendida inclusive a potestade legislativa" (PIMENTA, 1999, p. 153).

Coaduna com esse entendimento, Sarlet (2012) ao afirmar que "[...] todas as normas constitucionais, mesmo as que fixam programas ou tarefas para o Estado, possuem o caráter de autênticas normas jurídicas, no sentido de que mesmo sem qualquer ato concretizador se encontram aptas a desencadear algum efeito jurídico" (SARLET, 2012, p. 293).

Nesse sentido, a possibilidade de vir a reclamar a plenitude da eficácia de referidas normas no âmbito do Poder Judiciário, com a judicialização de políticas públicas, sem que se fale em ofensa ao princípio da separação de poderes, como explica Sarlet (2012, p. 293).

$\mathrm{O}$ direito ao meio ambiente ecologicamente equilibrado recebe relevante atenção do poder constituinte originário quando a CR/1988 o positiva como direito fundamental de terceira geração.

Nesse prisma, para o alcance ao direito fundamental ao meio ambiente ecologicamente equilibrado, está inserida a educação ambiental que, mesmo como norma programática, detém relevante função normativa, qual seja, a de atribuir fim ao Estado, desmistificando o liberalismo econômico (SILVA, 2001, p. 155).

Conforme previsão constitucional, para assegurar a efetividade do direito ao ambiente ecologicamente equilibrado, deve o Poder Público, de todas as esferas da Federação, "promover a educação ambiental em todos os níveis de ensino e a conscientização pública para a pre- 
servação do meio ambiente" (BRASIL, 1988, art. 225, § $1^{\circ}$, inciso VI). Nesse sentido, a educação ambiental é meio para que se atinja o meio ambiente ecologicamente equilibrado e, para tal, deve o Poder Público instituir políticas públicas que viabilizem referido instrumento.

Entretanto, pondera-se ser essa determinação constitucional uma norma meramente simbólica e, por tal, ineficaz. Mas ainda há outros pontos de suma importância a serem questionados, tendo em vista que a Lei $\mathrm{n}^{\circ} 9.795 / 1999$ veio para regulamentar a norma constitucional programática, destinando-lhe, a priori, eficácia.

Face todo exposto, ou seja, da existência de normas simbólicas, destaca-se a relevância dos princípios contidos no ordenamento jurídico brasileiro, os quais, também são diretrizes de aplicação do direito, juntamente com as leis postas.

Ademais, segundo Silva (2001, p. 156), apesar da natureza programática da lei de Educação ambiental, a destinando caráter simbólico, as normas programáticas "são normas que contêm, além de princípios esquemáticos para a atuação legislativa futura, também princípios gerais informadores de toda a ordem jurídica" (SILVA, 2001, p. 156).

Consiste em afirmar que apesar da dependência de atitudes positivas do Estado, as normas também apresentam princípios gerais norteadores de todo o ordenamento jurídico brasileiro.

Como muito bem descreve Pimenta (1999, p. 131), a Constituição é um sistema jurídico normativo aberto de regras e princípios, ultrapassando, assim, o jusnaturalismo, desconsiderando a dimensão puramente jurídica da Constituição. "Nesse contexto, a ideia de sistema constitucional denota as formas e as forças políticas inseridas na Constituição jurídica, vale dizer, exprime a constituição real" (PIMENTA, 1999, p. 1.310).

Referido autor (1999, p. 130-131) continua suas explanações afirmando ter restado evidente o acatamento no seio da sociedade da constituição jurídica, destinando-lhe maior eficácia.

Dentro dessa perspectiva, não se pode afirmar que a Constituição se caracteriza apenas por regras, mas também se consubstancia por princípios que, no contexto do presente artigo se fazem relevantes, tendo em vista os princípios da educação ambiental, já conclamados na Conferência Intergovernamental sobre Educação Ambiental ocorrida nos Estados Unidos - Tsibilisi, em 1977.

Em contraponto ao positivismo puro, encontra-se o método interpretativo de Dworkin (2002), com a respectiva valorização dos princípios norteadores de todo o ordenamento jurídico, arcabouço do neoconstitucionalismo. O posicionamento positivista clássico de compreender que apenas se existir uma lei específica é possível a aplicação do Direito, é o mesmo que ignorar a existência dos princípios, em uma herança positivista, criticada por Dworkin.

Desse modo, a proposta de interpretação perpetrada por Dworkin (2002), no que tange à questão da política, parece ponderável, pois quando se pretende uma abordagem crítica acerca de questão ambiental, improvável a afastabilidade do problema da esfera da teoria política.

Crítica destinada ao positivismo jurídico feita por Dworkin (2002), em sua teoria, consiste em como os juristas lidam com os enunciados, ao destinar-lhes significado, associando o direito à determinada questão. Nesse viés, o autor busca demonstrar o caráter interpretativo equivocado o qual o meio jurídico utiliza, vez que a sentido de hermenêutica usada pelos juristas não devem se pautar ao sentido presente no texto ou à intenção legislativa ao ocorrer determinada obscuridade. 
Assim, Dworkin (2002) busca estabelecer o saber jurídico para além da leitura dos códigos legais, em especial diante das consideráveis dificuldades concernentes às demandas que se referem ao conteúdo ambiental.

Nessa perspectiva, ao aduzir à educação ambiental um caráter principiológico, não há que se falar em ausência de obrigatoriedade prestacional, tendo em vista que, apesar da educação ambiental não ser propriamente um direito fundamental, é meio para alcançar o meio ambiente ecologicamente equilibrado, e está inserido no contexto da educação, que é um direito fundamental. Ademais:

\begin{abstract}
Os direitos fundamentais prestacionais de cunho programático constituem parâmetro para a interpretação, integração e aplicação das normas jurídicas (demais normas constitucionais e normas infraconstitucionais), já que contêm princípios, diretrizes e fins que condicionam a atividade dos órgãos estatais e influenciam, neste sentido, toda a ordem jurídica, resultando, ainda neste contexto, no condicionamento da atividade discricionária da Administração e di Poder Judiciário na aplicação, interpretação e concretização de suas normas e das demais normas jurídicas (SARLET, 2012, p. 297).
\end{abstract}

Nesse contexto, a relevância do método interpretativo de Dworkin (2002). Em sendo assim, mesmo que a legislação acerca da educação ambiental não seja suficiente para tornar a educação voltada ao meio ambiente eficaz, que então, com base nos princípios constitucionais, bem como nos direitos fundamentais da educação e do direito ao meio ambiente ecologicamente equilibrado, se dissemine a necessidade em se preservar o meio ambiente.

Em análise à educação ambiental, realizada em item a seguir, notar-se-á seu caráter principiológico, tendo em vista que a educação ambiental não é direito fundamental, mas princípio e, por tal, deve ser, segundo o filósofo Dworkin, considerado compreendido pelo arcabouço jurídico brasileiro e garantido pelo Poder Público.

\title{
2 ESPECIFICIDADES DA LEI DE EDUCAÇÃO AMBIENTAL E SUA PREVISÃO CONSTITUCIONAL
}

Com todas as mudanças ocorridas no decorrer da história e com a supervalorização do acúmulo de riquezas, em especial com o advento da Revolução Industrial, o ser humano distanciou-se de questões de suma relevância, como a preservação do meio ambiente.

Com o transcorrer dos anos, a humanidade viu-se diante de novas necessidades oriundas das ocorrências negativas que afetavam o meio ambiente e, consequentemente, suas vidas, já que o homem é parte integrante da natureza. E, por pertencer ao meio, o homem teve, pela CR/ 1988, positivada a proteção ao meio ambiente.

[...] relação do homem com o meio ambiente é objeto de proteção específica pelo sistema positivo brasileiro. A CF/881, em seu artigo 225, é taxativa em afirmar que a proteção do meio ambiente, direito das presentes e futuras gerações, insere-se no rol de direitos a serem protegidos pelo Estado [...] (BARRETO; MACHADO, 2016, p. 323).

Diante disso, iniciou-se processo de questionamento e providências no sentido de buscar minimizar os danos e preservar o meio. Uma das maneiras em prol de disseminar a necessidade de preservação da natureza é a educação.

Em um cenário mundial, a Conferência Intergovernamental sobre Educação Ambiental ocorrida em Tbilisi, 1977, foi um marco revolucionário, no sentido de que recomendou aprofundamento da função, dos objetivos e das características da educação ambiental, vindo a es- 
clarecer sua finalidade e princípios, oriundos da Declaração de Estocolmo (1972) e perpetrada na Carta de Belgrado (1975):

A partir da Conferência Intergovernamental sobre Educação Ambiental realizada
em Tbilisi (EUA), em 1977, inicia-se um amplo processo em nível global orientado
para criar as condições que formem uma nova consciência sobre o valor da natureza
e para reorientar a produção de conhecimento baseada nos métodos da interdisci-
plinaridade e nos princípios da complexidade. Esse campo educativo tem sido ferti-
lizado transversalmente, e isso tem possibilitado a realização de experiências con-
cretas de educação ambiental de forma criativa e inovadora por diversos segmentos
da população e em diversos níveis de formação (JACOBI, 2003, p. 190).

Diante do que foi preconizado em Tbilisi, observa-se a presença de alguns princípios inerentes à educação ambiental, dentre eles o de se tratar de processo dinâmico, perdurável, com a conscientização da sociedade e dos indivíduos, construindo conhecimento e possibilitando atitudes individuais, bem como de cunho coletivo em prol de solucionar problemas de viés ambiental.

Oportunamente, destaca-se que, no viés de educação ambiental eficaz, de cunho emancipatório, construir conhecimento não implica em desconsiderar saberes, tendo em vista o enunciado por Leff (2010), ao abordar a complexidade ambiental. Ele destacou o escopo do estudo ambiental que é, pois, um objeto socioambiental e, dessa forma, necessário se faz um saber ambiental. Nesse prisma:

\begin{abstract}
O saber ambiental não é contrário ao conhecimento; o que ele repugna é a abordagem (a)crítica. Enfim, esse saber tenta distanciar-se diametralmente dos princípios não holísticos disjuntivos, ao mesmo tempo em que produz princípios de matizes contextuais ecológicas. (BARBOSA; NÓBREGA, 2013, p. 186).
\end{abstract}

Princípio relevante da educação ambiental consiste também na contextualidade, observando a realidade particular das sociedades, sem negligenciar sua complexidade planetária. Nesse sentido:

A educação ambiental deve visar, no que se refere ao ensino, a transmitir aos alunos uma visão global da realidade em que eles estão inseridos e da qual são protagonistas, bem como fazer deles cidadãos imbuídos de valores humanistas e democráticos a serem colocados a serviço da humanidade e para o bem da coletividade (REIS; BIZAWU, 2014, p. 83).

Incorporada mais recentemente entre as características que a educação ambiental formal deve ter no Brasil, está a imposição de ser transversal, de modo que as questões ambientais não se vinculem a disciplina específica, transpassando demais conteúdos e orientações de cunho didático relacionadas a disciplinas diversas. Aufere-se, portanto, que a educação ambiental é assunto transversal constante dos. Parâmetros Curriculares Nacionais do Ministério da Educação (MEC).

Todavia, apesar desse caráter de transversalidade, e, em que pese a possibilidade de se ver inserida em debates presentes em diversas disciplinas curriculares, questiona-se a real efetividade da educação ambiental caso fosse implementada disciplina específica para a educação ambiental, sem, contudo, lhe retirar a característica de ser transversal. Tal abordagem será mais amplamente discutida em item próprio.

Diante disse, vê-se a abrangência, importância e intenções contidas nos preceitos da Conferência Intergovernamental sobre Educação Ambiental, de 1977, incorporados na CR/ 1988, e regulamentados pela Lei $n^{\circ}$ 9.795/1999.

No mais, em análise mais apurada e crítica ao estabelecido na Conferência de Tbilisi, nota-se, em seus princípios, o caráter de empregar enfoque interdisciplinar, examinando ques- 
tões ambientais em escalas locais, regionais, nacionais e internacionais, com foco em situações ambientais atuais e futuras, considerando, inclusive, a perspectiva histórica.

Nessa perspectiva, a integração holística, cada vez mais presente na comunidade mundial originou uma desterritorialização de adversidades jurídicas, de cunho constitucional que, como explica Neves (2009, p. 297), desvincularam-se do Estado. Tal se deve, em especial, ao fato de que o Estado não é mais o lugar inevitável de resolução de adversidades jurídicasconstitucionais atuando apenas como um dos diversos locais em que a colaboração em prol da solução do problema ocorre.

Com o meio ambiente e o desenvolvimento sustentável não poderia ser diferente, ante as alarmantes ocorrências ambientais que tanto vêm preocupando a humanidade. Os resultados nefastos ocorridos pelos danos ao meio ambiente não afetam somente em vias regionais, repercutindo sobre o globo terrestre em toda sua dimensão, ecoando, conforme se pode apurar dos ensinamentos de Neves (2009, p. 297) como problemática de cunho constitucional que afeta toda a sociedade internacional.

Dentro do que preconiza o instituto do transconstitucionalismo, trata-se, pois, de instrumento atuante na conjuntura mundial. Entretanto, na esfera do meio ambiente sustentável, não vislumbrou enfoque. Ressalta-se que, em relação às demandas ambientais solucionadas em caráter internacional deverão servir de parâmetros para decisões nacionais internas, haja vista ser o meio ambiente um só.

Ademais, ainda sob uma visão, mesmo que mais abrangente do transconstitucionalismo, a educação ambiental é instrumento universal de combate à degradação do meio ambiente, haja vista que está " [...] vinculada ao desenvolvimento de mentalidades, comportamentos e costumes baseados na preservação dos recursos naturais da Terra e na busca de um meio ambiente equilibrado a fim de criar um mundo melhor" (REIS; BIZAWU, 2014, p. 81).

Embora a CR/1988 não adote definição expressa de educação ambiental nem especifique conteúdos e formas de educação ambiental, relevantes aspectos podem ser discutidos no plano da análise jurídico-constitucional. E, mesmo que a CR/1988 não apresente definição expressa para educação ambiental, sabe-se que relevante intenção do direito ambiental consiste em educar comportamentos humanos com escopo maior de construir um direito constitucional voltado para a busca do meio ambiente ecologicamente equilibrado. Corrobora com essa afirmativa:

\footnotetext{
A finalidade da norma ambiental é a construção do direito constitucional ao meio ambiente ecologicamente equilibrado indispensável à sadia qualidade de vida. Portanto, o Direito Ambiental deve, sobretudo, estimular, educar comportamentos humanos conduzindo ao horizonte de sustentabilidade da relação do ser humano com a natureza, coerentemente com o direito fundamental prescrito no capítulo VI da Constituição Brasileira (DERANI; SOUZA, 2013, p. 252).
}

Ao tornar obrigatória a promoção da educação ambiental, ao lado de outras obrigações para o Poder Público (art. 225, §1º), a CR/1988 orienta-se no sentido de que não basta o uso de mecanismos de sanção e de promoção do direito na defesa e preservação do ambiente. Faz-se necessário promover a educação e a conscientização pública. Para Steinmetz (2009, p. 2), tratase da suposição de que o Direito pode ser insuficiente para a mudança de hábitos e o estímulo a comportamentos e atitudes comprometidos com a preservação ambiental.

Outro ponto relevante diz respeito à natureza da norma constitucional que impõe ao Poder Público a promoção da educação ambiental. Trata-se, pois, de regra ou de princípio? Partindo do pressuposto que, quanto à estrutura, as normas constitucionais distinguem-se em regras e princípios, adota-se, aqui, a interpretação de que a promoção da educação ambiental é 
princípio. Princípio definido conforme a teoria dos princípios de Dworkin, conforme já explanado.

Nesse viés, deve o princípio ser considerado ante a relevância em se preservar o meio ambiente, vindo a funcionar como instrumento eficaz para disseminar a necessidade de preservação da natureza, haja vista ser fonte norteadora de ações legislativas e do Poder Público.

Ao entender tal afirmação como certeira, não implica dizer que o Poder Público está livre para promover a educação ambiental em grau mínimo ou limitar-se a programas e projetos tímidos ou insuficientes de educação ambiental. Ao contrário, deve implementar a educação ambiental no máximo grau possível.

Nos ensinamentos de Steinmetz $(2009$, p. 2), não há um direito fundamental à educação ambiental, compreendido como um direito fundamental autônomo. A CR/1988 institucionaliza o direito fundamental à educação (art. $6^{\circ}$ da CR/1988) e situa a educação ambiental no âmbito da regulação constitucional do ambiente.

Nesse prisma, tem-se que há um direito fundamental ao ambiente ecologicamente equilibrado e o direito fundamental à educação, sendo esses, direitos fundamentais autônomos. A educação ambiental, segundo Steinmetz (2009, p. 2) é um dever objetivo do Poder Público entendido como um meio com o qual o Poder Público promove a efetividade do direito fundamental ao ambiente ecologicamente equilibrado. Assim, o dever de promover a educação ambiental é um dos deveres imputados ao Poder Público por força do direito fundamental ao ambiente ecologicamente equilibrado e pelo dever de se promover a educação.

Volta-se nesse ponto, à discussão entrelaçada aos princípios constitucionais e sua relevância para o ordenamento jurídico, bem como o método utilizado pelo filósofo Dworkin, já trazido à baila. Ademais, o princípio da promoção da educação ambiental articula-se também com os princípios da informação e da participação no âmbito das questões ambientais.

Por meio da educação, forma-se e informa-se. Com isso, criam-se os pressupostos cognitivos para a democratização das informações sobre o ambiente e, o que é mais importante, estimulam-se a curiosidade e a iniciativa pela busca da informação. Condizente afirmação de que pela informação educa-se. Nesse viés, educação e informação retroalimentam-se.

O conhecimento teórico pode ser adquirido por meio de instrumentos de repasse do conhecimento, inerentes à educação. Tem-se, segundo Jacobi (2003, p. 191-192), que educação não se refere tão somente à educação formal, mas também a meios como educação familiar, práticas sociais educativas de preservação ambiental e programas governamentais de divulgação da importância da preservação.

Nesse contexto, observa-se a importância da informação, que "assume um papel cada vez mais relevante, ciberespaço, multimídia, internet, a educação para a cidadania representam a possibilidade de motivar e sensibilizar as pessoas para transformar as diversas formas de participação na defesa da qualidade de vida" (JACOBI, 2003, p. 192-193).

Ponderação semelhante concernente entre educação e participação, haja vista que pessoas educadas estão mais predispostas à participação, ao exercício de seus direitos voltados para a formação da vontade estatal, contribuindo com ideias e ações na resolução de questões de interesse público, como são as questões ambientais. Há que se ressaltar que a educação qualifica a participação, ocasionando na condução de exigências mais rigorosas de programas e projetos de educação ambiental.

Viu-se a inexistência de conceituação de educação ambiental no texto constitucional. Todavia, a Lei $\mathrm{n}^{\circ}$ 9.795/1999 define educação ambiental como: 
Art. $1^{\circ}$ da Lei $n^{\circ} 9.795 / 1999$. [...] os processos por meio dos quais o indivíduo e a coletividade constroem valores sociais, conhecimentos, habilidades, atitudes e competências voltadas para a conservação do meio ambiente, bem de uso comum do povo, essencial à sadia qualidade de vida e sua sustentabilidade (BRASIL, 1999, art. $1^{\circ}$ ).

Essa definição orienta-se por uma visão dinâmica da educação ambiental. Dessa forma, tem-se que a educação ambiental não é concebida como conjunto estático de conhecimentos e informações sobre o ambiente a serem transmitidos para alguém que os receberá de maneira passiva. São processos que formam a educação ambiental. Sobre referidos processo, apresenta Steinmetz (2009):

\begin{abstract}
Esses processos são instrumentos que compreendem três dimensões: a axiológica, porque esses processos devem ser meios para a construção de valores sociais favoráveis ("amigos") da conservação do ambiente; a epistemológica (em sentido lato), porque esses processos devem produzir conhecimentos voltados para a conservação do ambiente; e praxeológica, porque devem desenvolver habilidades, atitudes $e$ competências voltadas para a conservação do ambiente. Essas dimensões estão interrelacionadas. Daí por que a lei estipula como um dos princípios básicos da educação ambiental "a vinculação entre a ética, a educação, o trabalho e as práticas sociais" (art. 4. ${ }^{\circ}$, IV, da Lei 9.795/1999) (STEINMETZ, 2009, p. 03).
\end{abstract}

Reforça a relevância da educação ambiental para assegurar a efetividade do direito ao ambiente ecologicamente equilibrado perpetrado no art. 225 da CR/1988, a Lei no 9.795/1999, ao determinar que: "a educação ambiental é um componente essencial e permanente da educação nacional, devendo estar presente, de forma articulada, em todos os níveis e modalidades do processo educativo, em caráter formal e não-formal” (BRASIL, 1999, art. $2^{\circ}$ ).

Nesse viés percebe-se a relevância dos atos administrativos normativos para a concretude da educação ambiental.

\title{
3 EDUCAÇÃO AMBIENTAL: SEUS ATOS ADMINISTRATIVOS NORMATIVOS E SUA EFETIVAÇÃO
}

Nos ensinamentos de Gomes (2012, p. 269), os atos administrativos normativos tornaram-se instrumentos da política educacional. No contexto da educação ambiental, diversos atos normativos, ligados ao Ministério do Meio Ambiente (MMA) e ao MEC devem ser considerados e, para tal, observados os atos que os envolvem. Alguns relatos importantes quanto aos atos administrativos normativos serão aqui abordados.

A educação ambiental no Brasil, segundo Leite e Medina (2001, p. 97) se inicia de maneira oficial a partir da criação da Secretaria de Meio Ambiente (SEMA) no ano de 1973, vinculada ao Ministério do Interior, vindo a responder às exigências internacionais que emergiam à época, no quesito ambiental e suas necessidades.

Em 31 de agosto de 1981 é instituída a Lei nº 6.938/1981, a qual dispõe sobre a Política Nacional do Meio Ambiente, seus fins e mecanismos de formulação e aplicação, sendo que, em seu art. $7^{\circ}$, cria o Conselho Nacional do Meio Ambiente (CONAMA).

A CR/1988, em seu art. 225 também faz remissão à educação ambiental. Em 1994, é ocasionada a aquiescência do Programa Nacional de Educação Ambiental - PRONEA, com a participação do MMA, MEC e do IBAMA.

Leite e Medina (2001, p. 105) esclarecem que o Ministério do Meio Ambiente, desde seu início, manifestou preocupação com a educação ambiental, vindo a promover inúmeras 
iniciativas, como por exemplo, a constituição de uma Comissão de Educação Ambiental do MMA de caráter inter e intra-ministerial, no âmbito da Secretaria de Desenvolvimento Integrado, em 1997, a participação na Câmara Técnica de Educação ambiental do CONAMA, etc. Contudo, somente em 1999, é instituída a Lei n 9.795/1999, a qual estabeleceu o PRONEA.

O Decreto $n^{\circ} 4.281 / 2002$ veio regulamentar a Lei $n^{\circ} 9.795 / 1999$, e criar o órgão gestor responsável pela coordenação da Política Nacional de Educação Ambiental, previsto no art. 14 da citada Lei $n^{\circ} 9.795 / 1999$, instituindo, em seu art. $1^{\circ}$, que:

\begin{abstract}
Art. $1^{\circ}$ do Decreto ${ }^{\circ}$ 4.281/2002. A Política Nacional de Educação Ambiental será executada pelos órgãos e entidades integrantes do Sistema Nacional de Meio Ambiente - SISNAMA, pelas instituições educacionais públicas e privadas dos sistemas de ensino, pelos órgãos públicos da União, Estados, Distrito Federal e Municípios, envolvendo entidades não governamentais, entidades de classe, meios de comunicação e demais segmentos da sociedade (BRASIL, 2002, art. $1^{\circ}$ ).
\end{abstract}

O MEC constrói, a partir das leis, pareceres e, da organização de atividades, a história da educação ambiental formal no Brasil. Serão relatados, dentre muitos, os principais atos administrativos normativos do MEC quanto à educação ambiental.

Em 1987, segundo Leite e Medina (2001, p. 97-105) o MEC aprova, no que tange à imprescritibilidade em acrescentar a educação ambiental nos currículos escolares de $1^{\circ}$ e $2^{\circ}$ graus, o parecer 226/87 do conselho Arnaldo Niskier. Em 1988, iniciam-se as atividades da Coordenação de Educação Ambiental do MEC. Em 1991, o MEC lança a portaria 678, instituindo que todos os currículos contemplarão conteúdos de educação ambiental, considerando os variados níveis de ensino. Em 1993 há, com o escopo de originar e propagar metodologias destinadas à educação ambiental, a criação dos centros de educação ambiental do MEC.

Diante dos atos administrativos normativos citados acima, nota-se o Estado exercendo a sua função regulamentar (GOMES, 2012, p. 269) no intuito em estabelecer critérios voltados para a educação ambiental, tanto no âmbito do MMA quanto do MEC. Todavia, pondera-se a respeito da efetivação da educação ambiental em especial o que tange ao estabelecido no art. 225 da CR/1988 e na Lei nº 9.795/1999, a qual institui a Política Nacional de Educação Ambiental após pouco mais de uma década de vigência da CR/1988.

A promoção da educação ambiental é um dever do Poder Público previsto pela CR/ 1988. Todavia, uma regulação infraconstitucional mais detalhada e abrangente da União entrou em vigor quando pouco tempo faltava para completar uma década de vigência do texto constitucional (Lei $\mathrm{n}^{\circ}$ 9.795/1999).

A lei acima mencionada foi regulamentada três anos após a edição do Decreto $n^{\circ} 4.281$ / 2002, que deu origem ao órgão responsável pela coordenação da Política Nacional de Educação Ambiental, previsto no art. 14 da Lei nº 9.795/1999.

Steinmetz (2009, p. 5) aduz que o problema quanto à real efetividade da Lei de Educação ambiental não está tão somente no quesito da morosidade legislativa, tão evidenciada quando se observa que o Decreto regulamentador de lei foi editado três anos após a mesma. Segundo o autor (2009), também está presente em outros pontos, como por exemplo, na acessibilidade aos sites das secretarias estaduais e municipais do meio ambiente e da educação, que ademais, apresentam informações insuficientes e obsoletas quanto aos projetos de educação ambiental.

Steinmetz (2009, p. 5) afirma ainda que, apesar de ser dever da coletividade defender e preservar o ambiente (art. 225, caput, CR/1988), as instituições privadas de ensino não destinam a devida atenção ao tema educação ambiental. Em que pese a Lei ${ }^{\circ}$ 9.795/1999 incumbir às instituições educativas, em todos os níveis, de "[...] promover a educação ambiental de 
maneira integrada aos programas educacionais que desenvolvem" (BRASIL, 1999, art. 30, inciso II) e instituir que a aprovação e supervisão para que as instituições de ensino e de seus cursos (tanto nas redes pública e privada) funcionem, devem observar o cumprimento das determinações da Lei no 9.795/1999, para a educação ambiental no ensino formal (art. 12), tais requisitos não vêm sendo cumpridos.

Cabe aqui a observação de que o poder de polícia, no que tange à fiscalização dos órgãos de educação não está acontecendo, tendo em vista a ausência, segundo Steinmetz (2009, p.6), do cumprimento dos quesitos constantes na Lei.

Concernente a outros pontos da Lei $n^{\circ}$ 9.795/1999, há, ainda, ponderações a serem realizadas, tendo em vista sua real efetividade. Exemplo plausível consiste no questionamento da opção legislativa de proibir a inserção da educação ambiental como disciplina singular no currículo de ensino, conforme art. $10, \S 1^{\circ}$. Leia-se:

\footnotetext{
É verdade que a educação ambiental é temática transversal. Mas isso não significa que necessariamente se deva proibir a criação de disciplina específica. Sobretudo considerando-se a complexidade científica e técnica das questões ambientais e da gravidade do atual estágio de degradação ambiental e dos riscos ambientais. Nem todos os docentes estão aptos teórica, metodológica e pedagogicamente a trabalhar com os temas ambientais, em sala de aula ou em atividades complementares (STEINMETZ, 2009, p. 6).
}

Nesse prisma, volta-se à discussão de não se tratar, a Lei de Educação Ambiental, de mera legislação simbólica, tendo em vista que sua função ideológica parece se sobrepor à sua função normativa, gerando a denominada hipertrofia normativa.

Para Steinmetz (2009, p. 7), não é possível afirmar tratar-se de legislação simbólica, tendo em vista seu caráter de lei com normas gerais, a qual veicula mais diretrizes vagas. "Contudo, pode-se afirmar que o grau de efetividade da lei é baixo, muito aquém do razoável, após 10 anos de vigência" (STEINMETZ, 2009, p. 7).

Nas instituições de ensino superior (IES) não são constatadas atividades de pleno exercício quanto à educação ambiental, notando-se a restrita iniciativa de professores e alunos, normalmente, direcionada para "pesquisa sobre educação ambiental como linha de pesquisa ou projeto de pesquisa, seja por meio de programas ou projetos setoriais ou pontuais de educação ambiental" (STEINMETZ, 2009, p. 5).

Ou seja, em relação ao ensino superior, a educação ambiental é pauta apenas de programas específicos, seja como linha ou projetos de pesquisa.

\section{FUNDAMENTOS DA EDUCAÇÃO AMBIENTAL: RETOMANDO O DEBATE CONTIDO NO PROBLEMA}

O debate contido no problema escopo do presente artigo consiste em efetuar análise da normatividade destinada à educação ambiental, instituída pela CR/1988. Tomou-se, por base, a Lei Federal no 9.795/1999, procurando examinar os principais pontos da regulação jurídica com o objetivo primordial de coadunar a educação ambiental enquanto meio para assegurar a efetividade do direito ao ambiente ecologicamente equilibrado, preconizado pelo art. 225 , caput, da CR/1988. Ao se efetuar análise crítica quanto a legislação destinada à educação ambiental, como, por exemplo, a proibição da existência de disciplina específica presente no âmbito curricular das instituições de ensino, acaba por priorizar o empenho individual dos profis- 
sionais com interesse a disseminar a educação ambiental, fazendo com que a educação ambiental, no parâmetros adotados por Loureiro (2012, p. 24), perca sua identidade.

Loureiro (2012, p. 24-25) aduz que, no campo do debate ambiental há um senso comum generalizado, de pouca profundidade, voltado para os conceitos, ocasionando o real motivo discursivo com o que se deseja e o que se deve fazer no campo educativo "ecológico, cidadão e crítico" (LOUREIRO, 2012, p. 24).

Não se busca estabelecer um modelo padrão de comportamento pedagógico entre os educadores ambientais, haja vista que:

\title{
[...] Educação Ambiental é parte dos planos ou, mais especificamente, de raciona- lidades de poder que são organizadas, planejadas, pensadas, definidas e materiali- zadas nos currículos escolares, com o objetivo de influenciar e transformar deter- minadas condutas humanas (OSÓRIO, 2011, p. 404).
}

Entretanto, é preciso elevar os padrões das atitudes individuais para um patamar mais amplo, no sentido de globalizar as ações, considerando, evidentemente, todo o complexo histórico e social em que está inserido o público alvo do projeto educacional. Nesse diapasão:

\begin{abstract}
Em Educação Ambiental, a negação da homogeneidade simplificadora e o respeito à diferença de ideias e modos de viver são fundamentais e coerentes com a visão de ambiente enquanto complexidade do mundo. Porém, ao se defender o diverso não se pode cair num pluralismo indiferenciado, em que as vivências pessoais e as lutas sociais se deem numa historia diluída e desconexa, na qual a negação, a confrontação de teorias e argumentos e a superação transformadora tornam-se impossíveis de se realizarem. Isso seria recair num relativismo absoluto e no atomismo de iniciativas que passam a ser vistas como válidas em si mesmas, posturas que em nada favorecem a consolidação da educação como atividade cidadã, reflexiva [...] (LOUREIRO, 2012, p. 26).
\end{abstract}

Significa dizer que, não desmerecendo as atitudes individuais, é preciso envolvimento e comprometimento dos órgãos públicos na busca por uma educação ambiental realmente eficaz.

Sem qualquer tipo de negligência quanto às dificuldades existentes para implementação de políticas públicas destinadas a esse fim, considerando que, no que tange à educação formal, sendo aquela instituída dentro das instituições de ensino, afirma-se a necessidade de um processo de execução um tanto quanto complexo, devido à necessidade de equipe multidisciplinar, com capacitação de profissional bem como das instituições.

Outro ponto consiste no fato de que, por depender de quesitos como orçamento e trabalho conjunto de políticas públicas das três esferas governamentais, assim como a ausência de profissionais gabaritados para praticar a educação ambiental formal, sua implantação seja negligenciada.

Não se pode olvidar a característica programática da legislação veiculada à educação ambiental. Entretanto, como salienta Sarlet (2012, p. 292), em que pese tratarem-se as normas programáticas de normas que apresentam normatividade insuficiente para alcançarem plena eficácia, "[...] porquanto se tratam de normas que estabelecem programas, finalidade e tarefas a serem implementadas pelo Estado, ou que contêm determinadas imposições de maior ou menor concretude dirigidas ao Legislador" (SARLET, 2012, p. 292), as mesmas devem ser obrigatoriamente instituídas, tendo em vista sua eficácia como autênticas normas jurídicas.

Ademais, como já defendido, por se tratar de princípio, a educação ambiental apresenta extrema relevância no ordenamento jurídico, devendo ser sopesado fatidicamente e interpretado segundo os critérios de Dworkin sem existir qualquer hierarquia entre os demais princípios, convivendo harmonicamente no ordenamento jurídico. 
Em suma, o Poder Público e os entes privados não levam a sério o princípio constitucional da educação ambiental enquanto mandamento direcionador das atividades voltadas para o alcance do meio ambiente ecologicamente equilibrado. A atuação, sobretudo do Poder Público, é insuficiente, sem que haja razões de cunho fático e/ou jurídico que a justifiquem na concretude, apesar dos enfoques tratados nesse artigo.

\section{CONSIDERAÇÕES FINAIS}

Admitir a necessidade em preservar o meio ambiente é questão pacificada. Os meios para disseminar essa necessidade é que ainda são objetos de análise e a educação ambiental é um instrumento hábil para disseminar a demanda de se preservar o meio ambiente, alertando a sociedade dos riscos num futuro não muito distante, acaso esgotados os recursos naturais.

Sabe-se não ser tarefa fácil alterar paradigmas pela ruptura de obstáculos epistemológicos e barreiras institucionais. Todavia, diante da situação de crise ambiental em que vive o planeta, faz-se necessário a busca por novas concepções.

O direito possui papel fundamental nesse processo transformador, pois, enquanto instrumento de organização da sociedade, move a dinâmica social na direção desejada. Mas, como relatado no transcorrer do trabalho, o caráter punitivo das sanções por si só não são capazes de moldar comportamentos, pela ausência de transposição do saber. Assim, os instrumentos de gestão de comando e controle, por si só, não são eficientes para a consecução dos objetivos do Direito ambiental.

A educação, por sua vez, possui papel de instrumento de viabilização pelo qual se busca modificar a consciência humana, perpetrando comportamentos desejáveis. Ao se considerar que as normas de proteção ao meio ambiente não se destinam necessariamente a modificações radicais da relação homem natureza, almeja-se que a educação ambiental desempenhe essa função.

Apesar da lei de educação ambiental possuir pouco mais que dezesseis anos, sua efetivação ainda é discutida, tendo em pauta a ausência de sua aplicação, seja consubstanciada em justificativas organizacionais, orçamentárias, de cunho profissionalizante, pela ausência de profissionais gabaritados para a sua prática ou por mero descaso governamental.

Diante disso, trata-se de legislação simbólica, relacionando-a a ineficácia vinculada a necessidade de regulamentação ou aplicação insuficiente. Contudo, pondera-se que, pelo fato de se tratar de norma jurídica, independentemente de se referir a uma norma programática, sua eficácia jurídica é inquestionável, sendo quesito suficiente para exigir sua aplicabilidade junto ao Poder Judiciário, sem, contudo, consubstanciar vedação ao princípio da separação dos poderes.

Em que pese a educação ambiental não ser direito fundamental consagrado no texto da CR/1988, é princípio e, segundo os critérios do filósofo Dworkin (2002), apresenta extrema relevância no ordenamento jurídico pátrio. Ademais, encontra-se vinculado ao direito fundamental da educação e é instrumento de alcance do direito fundamental ao meio ambiente ecologicamente equilibrado, além de que se encontra intimamente ligado aos princípios da informação e da participação.

Assim, conclui-se que a ausência de efetivação da lei de educação ambiental caracteriza o descaso do Poder Público, bem como dos entes privados, que não destinam a devida serieda- 
de ao postulado constitucional da educação ambiental enquanto mandamento direcionador das atividades voltadas para o alcance do meio ambiente ecologicamente equilibrado.

\section{REFERÊNCIAS}

BARBOSA, Erivaldo Moreira; NÓBREGA, Maria de Fátima. O Direito ambiental em perspectiva: da hermenêutica-sistêmica ao saber ambiental. Revista Veredas do Direito, Belo Horizonte, ž v. 10, no 20, p. 179-205, jul./dez. 2013. Disponível em: <http:// www.domhelder.edu.br/mestrado>. Acesso em: 06 dez. 2017.

BARRETO, Leandro de Marzo; MACHADO, Paulo Affonso Leme. A construção do diálogo e da solidariedade e a proteção do bem ambiental e da natureza na concepção universal do humano, a partir de uma leitura da Encíclica Laudato Si. Revista Veredas do Direito, Belo Horizonte, v. 13, n ${ }^{\circ}$ 26, p. 319-336, maio/ago. 2016. Disponível em: <http:// www.domhelder.edu.br/mestrado>. Acesso em: 06 nov. 2016.

BRASIL. Constituição da República Federativa do Brasil de 1988. Diário Oficial da União, Brasília, 05 out. 1988.

BRASIL. Decreto-lei no 4.281, de 25 jun. 2002. Regulamenta a Lei no 9.795, de 27 de abril de 1999, que institui a Política Nacional de Educação Ambiental, e dá outras providências. Diário Oficial, Brasília, 26 jul. 2002. Disponível em: <http://www.planalto.gov.br/ccivil_03/decreto/ 2002/D4281.htm>. Acesso em: 20 set. 2016.

BRASIL. Lei $n^{0}$ 9.795, de 27 abr. 1999. Dispõe sobre a educação ambiental, institui a Política Nacional de Educação Ambiental e dá outras providências. Diário Oficial, Brasília, 28 abr. 1999. Disponível em: <http://www.planalto.gov.br/ccivil_03/decreto/2002/D4281.htm>. Acesso em: 20 set. 2016.

CANOTILHO, José Joaquim Gomes. Direito constitucional e teoria da Constituição. 7. ed. Coimbra: Almedina, 2003.

DERANI, Cristiane; SOUZA, Kelly Schaper Soriano de. Instrumentos econômicos da política nacional do meio ambiente: por uma economia ecológica. Revista Veredas do Direito, Belo Horizonte, v. 10, $\mathrm{n}^{\mathrm{o}}$ 19, p. 247-272, jan./jun. 2013. Disponível em: <http:// www.domhelder.edu.br/mestrado>. Acesso em: 14 maio 2016.

DWORKIN, Ronald. Levando os direitos a sério. Tradução de Nelson Boeira. São Paulo: Martins Fontes, 2002.

GOMES, Magno Federici. Direito educacional superior: evolução, legislação, procedimentos administrativos e função normativa. Curitiba: Juruá, 2012.

JACOBI, Pedro. Educação ambiental, cidadania e sustentabilidade. Cadernos de Pesquisa, online, $\mathrm{n}^{\mathrm{o}}$ 118, p. 189-205, mar. 2003. Disponível em: <http://www.scielo.br/pdf/cp/n118/ 16834.pdf>. Acesso em: 21 abr. 2016.

LEFF, Enrique. Epistemologia ambiental. Tradução de Sandra Valenzuela. 5 ed. São Paulo: Cortez, 2010.

LEITE, Ana Lúcia Tostes de Aquino; MEDINA, Naná Mininni (Coord.). Educação ambiental; curso básico a distância: documentos e legislação da educação ambiental. 2. ed. Brasília: MMA, 2001. v. 5. 
LOUREIRO, Carlos Frederico Bernardo. Trajetória e fundamentos da educação ambiental. 4. ed. São Paulo: Cortez, 2012.

NEVES, Marcelo. Transconstitucionalismo. São Paulo: WMF Martins Fontes, 2009.

PIMENTA, Paulo Roberto Lyrio. Eficácia e aplicabilidade das normas constitucionais programáticas. São Paulo: Max Limonad, 1999.

OSÓRIO, Mara Rejane Vieira. Professores e educação ambiental: implicações para o currículo. Revista Brasileira de Estudos Pedagógicos, Brasília, v. 92, no 231, p. 399-416, maio/ago. 2011. Disponível em: <http://rbep.inep.gov.br/index.php/rbep/article/view/554>. Acesso em: 06 dez. 2017.

REIS, Émilien Vilas Boas; BIZAWU, Sébastien Kiwonghi. Educação ambiental como processo para a construção da cidadania. In: COSTA, Beatriz Souza; REZENDE, Elcio Nacur (org.). Temas essenciais em Direito ambiental: um diálogo internacional. Rio de Janeiro: Lumen Juris, 2014. Cap. 3. p. 67-95. v. 4. Coleção de Direito ambiental e desenvolvimento sustentável. Dom Helder Câmara.

SARLET, Ingo Wolfgang. A eficácia dos direitos fundamentais: uma teoria geral dos direitos fundamentais na perspectiva constitucional. 11. ed. Porto Alegre: Livraria do Advogado, 2012.

SILVA, José Afonso da. Aplicabilidade das normas constitucionais. 5. ed. São Paulo: Malheiros, 2001.

STEINMETZ, Wilson. Educação ambiental, Constituição e legislação: análise jurídica e avaliação crítica após dez anos de vigência da Lei 9.795/1999. Revista de Direito ambiental, São Paulo, v. 15, nº 55, p. 189-202, jul./set. 2009.

Recebido em: 17 mar. 2017. Aceito em: 3 jan. 2018. 